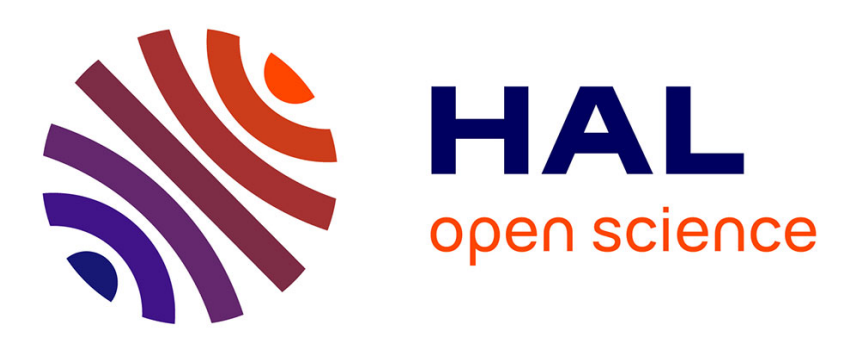

\title{
Reactivity of the Ti-Al system: Experimental study and molecular dynamics simulations
}

Q. Bizot, O. Politano, A. Nepapushev, S. Vadchenko, A. Rogachev, Florence Baras

\section{- To cite this version:}

Q. Bizot, O. Politano, A. Nepapushev, S. Vadchenko, A. Rogachev, et al.. Reactivity of the Ti-Al system: Experimental study and molecular dynamics simulations. Journal of Applied Physics, 2020, 127 (14), pp.145304. 10.1063/5.0004550 . hal-02995065

\section{HAL Id: hal-02995065 \\ https://hal.science/hal-02995065}

Submitted on 10 Nov 2020

HAL is a multi-disciplinary open access archive for the deposit and dissemination of scientific research documents, whether they are published or not. The documents may come from teaching and research institutions in France or abroad, or from public or private research centers.
L'archive ouverte pluridisciplinaire HAL, est destinée au dépôt et à la diffusion de documents scientifiques de niveau recherche, publiés ou non, émanant des établissements d'enseignement et de recherche français ou étrangers, des laboratoires publics ou privés. 
Reactivity of the Ti-Al system: experimental study and molecular dynamics simulations

Q. Bizot, ${ }^{1}$ O. Politano, ${ }^{1}$ A.A. Nepapushev, ${ }^{2}$ S.G. Vadchenko, ${ }^{3}$ A.S.

Rogachev, ${ }^{2,3}$ and F. Baras ${ }^{1,}$ a)

1) Laboratoire Interdisciplinaire Carnot de Bourgogne,

UMR 6303 CNRS-Université Bourgogne Franche-Comté,

21078 Dijon, France

2) National University of Science and Technology MISiS, Leninsky prospect 4, Moscow, 119049 Russia

${ }^{3)}$ Merzhanov Institute of Structural Macrokinetics and Materials Science

Russian Academy of Sciences (ISMAN), Chernogolovka, Moscow Region, 142432 Russia

(Dated: 10 November 2020) 
The reactivity of the Ti-Al system was investigated experimentally in the case of reactive laminated particles produced by High Energy Ball Milling. The ignition temperature for self-sustaining reaction was measured as a function of the heating rate. By means of the Kissinger analysis, two activation energies were evaluated. The first one is associated to the solid state transformation at interface below the melting point of Al. The second one corresponds to the exothermic dissolution of $\mathrm{Ti}$ into $\mathrm{Al}$ liquid together with the formation of $\mathrm{TiAl}_{3}$. A complementary microscopic approach was developed in order to detect all elemental processes associated the reactivity of the Ti-Al system in composite materials. Above the melting temperature of $\mathrm{Al}$, the exothermic dissolution of $\mathrm{Ti}$ into the liquid layer starts and induces a self-sustaining behavior until the reaction is complete. The dissolution step is limited by the low solubility of Ti in Al. The formation of the intermetallic compound $\mathrm{TiAl}_{3}$ was observed. The microscopic analysis of the dissolution at interface explains some specific features of reactive particles.

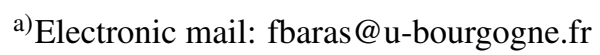




\section{INTRODUCTION}

Research on Ti-Al based intermetallic alloys is an active research field due to their possible use in aircraft engines, industrial gas turbines, and automotive industries. These materials exhibit unique physical and mechanical properties such as very good strength, high specific yield strength and stiffness, good oxidation resistance combined with good creep properties at high temperatures, low density, high thermal capability and biocompatibility, ... . Actually, titanium aluminides is an important class of materials that could provide a promising alternative to nickel alloys. In the last decades, the class of Ti-rich Ti-Al based intermetallic materials has replaced many usual alloys for applications up to $900{ }^{\circ} \mathrm{C}(1173 \mathrm{~K})$. For instance, the Ti lamellar alloys $\left(\gamma-\mathrm{TiAl}+\alpha_{2}-\mathrm{Ti}_{3} \mathrm{Al}\right)$ are already used in industrial applications due to strength and ductility requirements at high temperature.

A major issue is to use refractory Ti-Al intermetallic alloys in additive technologies. This is actually challenging because 3D printing by SLM (Selective Laser Melting) and SLS (Selective Laser Sintering) uses a local heating that must be close to the high melting point of refractory powder particles. In order to overcome the technological bottleneck, an alternative is the fabrication of composite reactive particles $\mathrm{Ti}+\mathrm{Al}$ that react at low temperature and lead to the direct formation of intermetallic alloys ${ }^{2}$. In parallel, a new method for fabricating Ti-Al intermetallic compounds by cold spraying was proposed $\mathrm{in}^{3}$.

Reactive multilayer nanofoils (RMNF) present very close similarities with reactive laminated particles (RLP). They are often used as model systems to study the processes occurring at the atomic scale in metallic nano-systems presenting a huge amount reactive interfaces. RMNFs are composed of hundreds of stacked thin metallic layers, varying in thickness from 4 to $100 \mathrm{~nm}$. In such bimetallic Ti/Al nanofoils, a short-term local heating will induce a rapid and self-sustaining reaction ${ }^{4}$. The exothermic reaction propagates along the foil without any further energy supply. The propagation velocity of the reaction is up to $3 \mathrm{~m} / \mathrm{s}^{5,6}$. The overall reaction temperature is higher than the 
melting temperature of $\mathrm{Al}\left(T_{m}=660^{\circ} \mathrm{C}(933 \mathrm{~K})\right)$ and lower than the melting temperature of $\mathrm{Ti}\left(T_{m}=1650{ }^{\circ} \mathrm{C}(1923 \mathrm{~K})\right)$. Thus, the reaction proceeds in a liquid/solid system. A Ti-Al foil is transformed in intermetallics in less than $50 \mathrm{~ms}$. The kinetics of intermetallic phase formation in the Ti/Al multilayers has been investigated using differential scanning calorimetry and time-resolved X-ray diffraction ${ }^{7,8}$.

Many questions arise concerning the reactivity of the Ti-Al system in RMNFs. In order to address this issue, we adopted a molecular dynamics approach that gives a full microscopic description. This approach has been extensively applied in the case of Ni/Al RMNFs (for a review, see ${ }^{9}$ ). Molecular dynamics simulations (MDS) reveal the elemental mechanisms that occur at nanoscale: melting, dissolution, mixing, phase transformations, microstructure formation, nucleation and growth of intermetallics, ... Such analysis allows us to describe the complex kinetics occurring in metallic systems provided a satisfactory interatomic potential is available. There exists a limited number of studies of the Ti-Al system by means of molecular dynamics. The alloying reaction in Ti-coated $\mathrm{Al}$ nanoparticle (4.8 nm of diameter in equiatomic fraction) was studied by means of MDS in combination with an Embedded Atom Method (EAM) potential ${ }^{10}$. The alloying reaction occurs as a metastable solid-state alloying process that completes after the melting of the $\mathrm{Al}$ core. After an heating up to $900 \mathrm{~K}$, the exothermic alloying reaction heats up the system to an adiabatic temperature of $1352 \mathrm{~K}$. The final product is an undercooled liquid $\mathrm{Ti}_{50} \mathrm{Al}_{50}$ alloy. The Al-coated Ti nanoparticle is much less reactive because of pre-alloying in the vicinity of the interface ${ }^{11}$. The synthesis of the intermetallic $\gamma$-TiAl was studied by means of MDS in the thermal explosion regime ${ }^{12}$. Heterogeneous crystallization from the melt was observed at $1550 \mathrm{~K}$ when the system is submitted to cooling ${ }^{13}$. The heterogeneous nucleation of solid Al from the melt by $\mathrm{TiAl}_{3}$ was investigated ${ }^{14}$. It appears that the intermetallic $\mathrm{TiAl}_{3}$ is a powerful nucleant for the solidification of aluminum.

A recent experimental work ${ }^{2}$ demonstrates the peculiar features of Ti-Al RLPs produced by High Energy Ball Milling. First, a preliminary heating is required for the onset 
of a self-sustaining reaction. The ignition temperature is close to the melting point of Al. Actually, the formation of liquid Al promotes the exothermic dissolution of Ti into Al liquid that induces a temperature rise. The combustion of Ti-Al RLPs leads to the

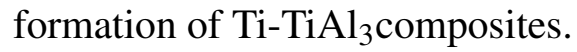

In this work, we focused on the reactivity of composite Ti-Al systems by combining an experimental investigation and MD study. In the experimental part, the aim is to detect the key aspects of the exothermic reaction as the reaction onset temperature and the characteristic activation energy. In the MD part, the understanding of the reaction mechanism is directly related to the question of phase transformations associated with the self-propagating reactive wave. To handle this problem by means of molecular dynamics, the atomic and microstructure evolution inside the stacked layers was simulated at a fixed temperature. Two representative systems were prepared: a small system (reference system) and a thick system. Different initial temperatures close to the melting temperature of $\mathrm{Al}$ were imposed for the same stoichiometry $N_{\mathrm{Ti}} / N_{\mathrm{Al}} \sim 3$ with an excess of Ti. This allowed accurate description of reactive dissolution and crystallization of intermetallic compound during the progress of the reaction.

\section{METHODS}

\section{A. Experimental methods}

Composite Ti/Al powders were produced by means of High Energy Ball Milling (HEBM) technique in the planetary mill "Activator-2S" ("Activator", Russia), from the mixture of $\mathrm{Ti}$ and $\mathrm{Al}$ elemental powders. The powders were placed in the steel jars together with steel balls. Volume of the jar was $250 \mathrm{ml}$ (filled with Ar at 4 bar), diameter of the steel balls $6 \mathrm{~mm}$, balls to mixture mass ratio 20:1, the rotation speed of Sundisc $200 \mathrm{rpm}$, milling time $120 \mathrm{~min}$. After HEBM, the powder consisted of bimetallic particles, were Ti flattened inclusions were embedded into Al matrix: thus, Al layers separated Ti islands in each bimetallic particle. Reactivity of the composite powders 
were evaluated by heating up mini-pellets ( $3 \mathrm{~mm}$ in diameter, $0.3-1.0 \mathrm{~mm}$ thick), consolidated from the composite powder, in Ar atmosphere, and measuring reaction onset temperature $T_{i}$. Details of the methods were published earlier ${ }^{2}$. Microstructure and elements distribution inside the bimetal particles were studied using SEM and EDS analyses. Basing on the Kissinger method ${ }^{15}$, energy of activation $E$ was evaluated from the formula

$$
\ln \left(\frac{b}{T_{i}^{2}}\right)=\mathrm{const}-E /\left(R T_{i}\right)
$$

where $b=d T / d t$ - heating rate, $T_{i}$ - reaction onset temperature, $R$ - gas constant. We used $T_{i}$ instead of the temperature corresponding to maximum reaction rate, $T_{m}$, because, as distinct from differential scanning calorimetry, temperature in our experiments increased very sharply after reaction initiation. Thus, value of $T i$ was close to $T m$, which allowed evaluation of $E$ from eq. (1).

\section{B. Simulation details}

The molecular dynamics (MD) simulations were performed with the LAMMPS MD software $^{16}$. The system was analyzed at the atomistic level using the EAM interatomic potential developed by Zope and Mishin in $2003^{17}$.The potential of Zope and Mishin was initially fitted for $\mathrm{Al}, \alpha$-Ti and $\gamma$-TiAl using extended experimental and ab-initio databases and its transferability was then tested by considering other intermetallic compounds (i.e., $L 1_{0}-\mathrm{TiAl}, L 1_{2}-\mathrm{TiAl}_{3}$ and $D 0_{22}-\mathrm{TiAl}_{3}$ ). A preliminary step consisted in computing the melting temperature (see Table 1) using a classical liquid-solid coexistence (two-phase) method ${ }^{18}$. Thermal expansion coefficient was also determined to characterize the behavior of the system as a function of temperature (see Appendix).

In order to model the Ti-Al reactive interfaces in RLPs, a simplified bilayer Ti-AlTi system was considered. The initial system (see Fig. 1), referred to here as the small sample, is made of an inner layer of fcc- $\mathrm{Al}$ (7 atomic planes containing $10188 \mathrm{Al}$ atoms) in between two outer layers of hcp- $\mathrm{Ti}$ ( 8 and 9 atomic planes each containing all together 


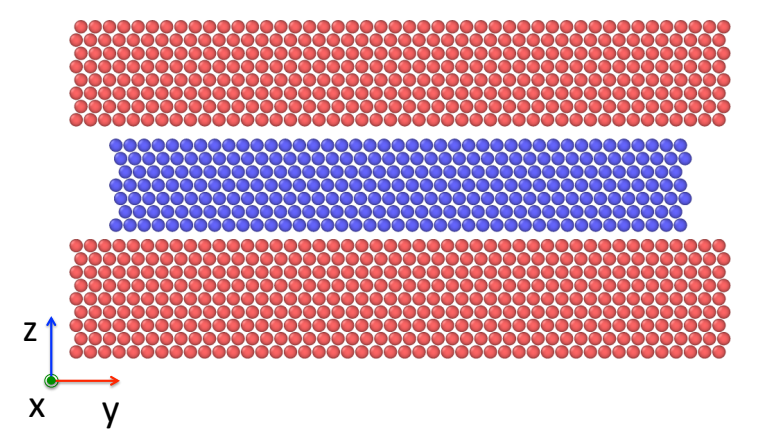

FIG. 1. Initial configuration of the simulated system with one slice of $\mathrm{Al}$ in between two Ti layers. $\mathrm{Al}$ and $\mathrm{Ti}$ are shown as blue and red spheres, respectively. (For interpretation of the references to color in this figure legend, the reader is referred to the web version of this article.)

\begin{tabular}{|c|c|c|c|c|}
\hline & \multicolumn{3}{|c|}{ Melting temperatures (K) } & Cohesive energies (eV/atom) \\
\hline metal/phase & two-phase method & other works & experimental & EAM potential vs. experimental \\
\hline $\mathrm{Al}$ & 870 & 870 & 933 & $3.36 / 3.36$ \\
$\mathrm{Ti}$ & 1531 & - & 1941 & $4.85 / 4.85$ \\
$\mathrm{TiAl}$ & 1510 & 1494 & 1713 & $4.51 / 4.51$ \\
$\operatorname{TiAl}_{3}\left(D_{22}\right)$ & 1175 & - & 1388 & $4.02 / 4.06$ \\
\hline
\end{tabular}

TABLE I. Melting temperatures and cohesive energies evaluated using the Zope and Mishin EAM potential and experimental values.

31280 atoms) with $N_{\mathrm{Ti}} / N_{\mathrm{Al}} \sim 3$. The size of the simulation box is $L_{x}=L_{y}=11.8 \mathrm{~nm}$ in the $x$-direction and $L_{z}=6 \mathrm{~nm}$ in the $z$-direction. The interface is oriented normal to the [002] direction of the Ti layers and to the [111] direction of Al layer. Periodic boundary conditions are applied in all directions. The empty space around the Al layer allows the system to avoid any artificial constraint due to the application of periodicity on the $\mathrm{Al}$ and $\mathrm{Ti}^{19}$.

Both $\mathrm{Al}$ and Ti lattice parameters were determined as a function of temperature on bulk systems. Hence, the Ti-Al-Ti system was created with the appropriate lattice pa- 


\begin{tabular}{|c|c|c|c|c|}
\hline & \multicolumn{4}{|c|}{$N_{\mathrm{Ti}} / N_{\mathrm{Al}} \sim 3$} \\
\hline sample & $L_{x}=L_{y}(\mathrm{~nm})$ & $L_{z}(\mathrm{~nm})$ & $\mathrm{Al}$ atomic planes & $\#$ atoms \\
\hline Reference system & 11.8 & 6.1 & 7 & 41468 \\
Thick sample & 17.5 & 13.4 & 15 & 211710 \\
\hline
\end{tabular}

TABLE II. Summary of the simulation details

rameter corresponding to the initial temperature (see Appendix). The simulation is thermalized in the canonical statistical ensemble (NVT) over 400 ps at the initial temperature using a Nosé-Hoover thermostat (damping parameter of 0.1 ). The simulation is then carried out in the microcanonical statistical ensemble (NVE) over more than $15 \mathrm{~ns}$. NVE simulation corresponds to adiabatic conditions: no external reservoir is interacting with the system. This procedure allows us to observe the spontaneous dynamics of the system that may imply a variety of elemental mechanisms. The time step to integrate the equation of motions with a Verlet algorithm was fixed at $0.001 \mathrm{ps}$.

A thick sample was also considered (see Table II). Initially, an inner layer of fccAl with of 15 atomic planes $\left(N_{\mathrm{Al}}=51230\right)$ was placed in between two outer layers of hcp-Ti with 40 atomic planes each $\left(N_{\mathrm{Ti}}=160480\right)$ with $N_{\mathrm{Ti}} / N_{\mathrm{Al}} \sim 3$. The size of the simulation box is $L_{x}=L_{y}=17.5 \mathrm{~nm}$ in the $x$-direction and $L_{z}=134 \mathrm{~nm}$ in the $z$ direction. The orientations of $\mathrm{Ti}$ and $\mathrm{Al}$ at interface was $(002) /(111)$ as in the previous simulations. The simulation procedure is in two parts:

- The system is thermalized in the NVT ensemble before the simulation in adiabatic conditions (NVE ensemble).

- The system is then cooled down by step of $5 \mathrm{~K}$ in the NPT ensemble (Parrinello and Rahman scheme with a damping parameter of 0.1) during 300 ps and the NVT ensemble during 100 ps. After each step, the simulation is carrying out in the microcanonical ensemble (NVE) in order to observe the spontaneous dynamics of the system. The cooling process begins at $1315 \mathrm{~K}$ and ends at $1200 \mathrm{~K}$. 
Different indicators are used to follow the evolution of the system. The number density profiles along the $z$-axis gives a good indication of the crystallinity state and of the local composition in $\mathrm{Ti}$ or $\mathrm{Al}$ in each slice. Well-defined peaks are associated with a system structured in atomic planes. Each atom was labeled by two indices: one associated with the chemical species (type) and one with its local lattice structure (Ackland and Jone's indicator $)^{20}$. It is also useful to compute the potential energy per atom, which is very sensitive to the local environment of a given atom. Global indicators were also followed during the evolution of the system: temperature and the stoichiometry in the inner layer. The stoichiometry is defined as the ratio $\xi=N_{\mathrm{Ti}} /\left(N_{\mathrm{Ti}}+N_{\mathrm{Al}}\right)$. The microscopic configurations were visualized with the open-source software (OVITO $)^{21}$.

\section{RESULTS AND DISCUSSIONS}

\section{A. Experimental results}

After HEBM, both metals ( $\mathrm{Ti}$ and $\mathrm{Al}$ ) formed bimetal particles (Fig. 2a). More ductile metal Al forms matrix, where Ti layers (inclusions) have irregular shape. No intermetallic phases were observed at the boundaries between $\mathrm{Al}$ and $\mathrm{Ti}$ (Fig. 2b). At the same time, some intermixing of these two metals was revealed due to line-scan mode of EDS microanalysis (Fig. 3). A typical microstructure of the intermixed areas looks similar to metastable phases that formed in the Ni-Al systems during HEBM due to intense friction ${ }^{22}$. It allows us to assume that metastable phases (perhaps, solid solutions) can be formed due to HEBM also in the Ti-Al system, which should decrease temperature of the reaction initiation in this system.

In order to measure the reaction initiation temperature, the mini-pellets were placed in the h-BN crucible and heated up using carbon-strip heater with average rate from 18 $\mathrm{K} / \mathrm{s}$ up to $119 \mathrm{~K} / \mathrm{s}$. Typical temperature - time profile of the process is shown in Fig. 4. When the temperature of the sample achieved some value $T_{i}$, exothermal reaction started and increased temperature sharply. The heating regime below $T_{i}$ does not follow 

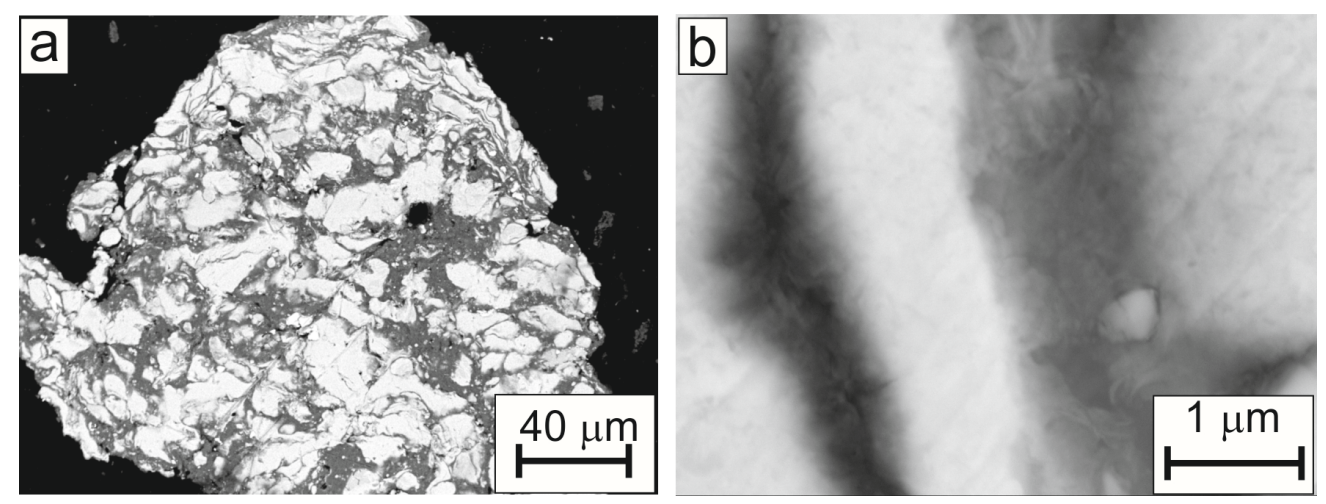

FIG. 2. Microstructure of the bimetal particle after HEBM (a) and boundaries between $\mathrm{Ti}$ and Al layers (b). SEM, backscattered electrons. Dark phase is Al, white - Ti.

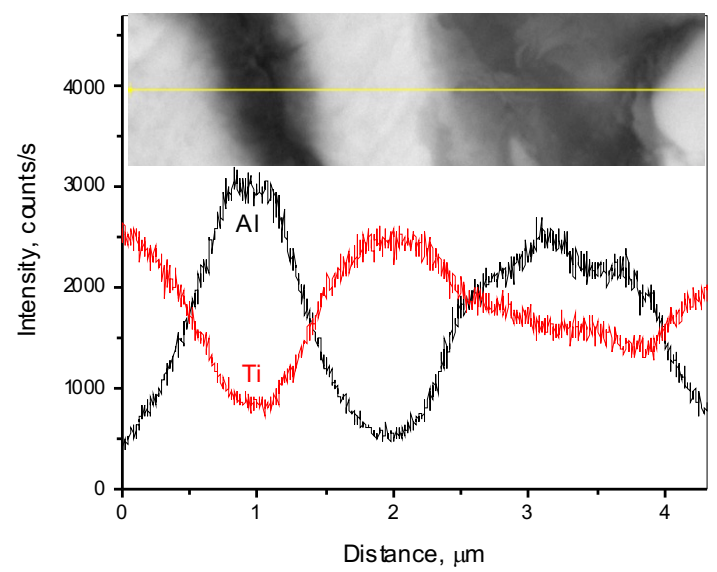

FIG. 3. SEM and results of the EDS scanning along the line. Dark phase - Al, white - Ti, grey intermediate metastable phase.

strictly a linear law, however, average heating rate can be calculated for the sake of rough approximation as

$$
b=<d T / d t>=\left(T_{i}-T_{0}\right) / t_{i},
$$

where $T_{i}$ - the reaction onset temperature, $T_{0}$ - initial temperature of the sample, and $t_{i}$ - heating time. The carbon heater was switched-off in $1 \mathrm{~s}$ after exothermic reaction initiation, and the sample cooled down. 


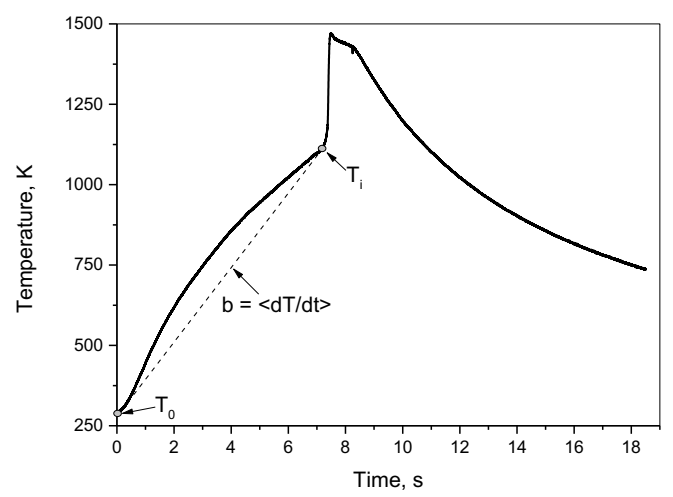

FIG. 4. Temperature-time profile of the heating up and reaction in Ti/Al composite powder sample measured with WRe5/WRe20 thermocouple.

The value of $T_{i}$ increased continuously with increasing heating rate $b$ (Fig. 5). Based on these data, the Kissinger equation (1) was applied to evaluate activation energy of the process:

$$
E \sim-R \frac{d\left[\ln \left(b / T_{i}^{2}\right)\right]}{d\left(1 / T_{i}\right)}
$$

Two linear regions were appeared at the Kissinger plot (Fig. 6) that correspond to the values of activation energy $E_{1}=(28.4 \pm 7.3) \mathrm{kJ} / \mathrm{mol}$ for higher temperature, and $E_{2}=(92.1 \pm 14.4) \mathrm{kJ} / \mathrm{mol}$ for lower temperature regions. A transition point between these two regions corresponds to a temperature of about $950-960 \mathrm{~K}$, which is close to the melting point of $\mathrm{Al}(933.5 \mathrm{~K})$. Thus, we can assume that limiting stage of the process changes, when $T_{i}$ exceeds melting temperature of Al. Probably, under slow heating conditions (smaller $b$ ), reaction has enough time to form some solid intermetallic product on the boundary between $\mathrm{Ti}$ and $\mathrm{Al}$, which later limits the reaction rate even after Al melts. At fast heating (larger $b$ ), no solid product appears, and the reaction is limited only by diffusion in the melt, with small energy of activation.

Although the two measured values of $E$ definitely indicate two different mechanisms of interaction, it remains a challenge to reveal these mechanisms. Diffusion coefficient and activation energy of $\mathrm{Ti}$ atoms in the $\mathrm{Al}$ melt are not available up to now. The activa- 


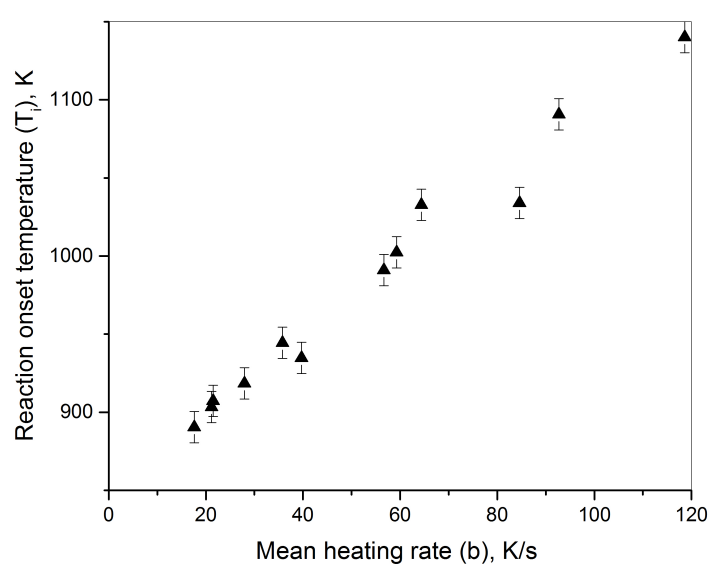

FIG. 5. Reaction onset temperature as function of heating rate.

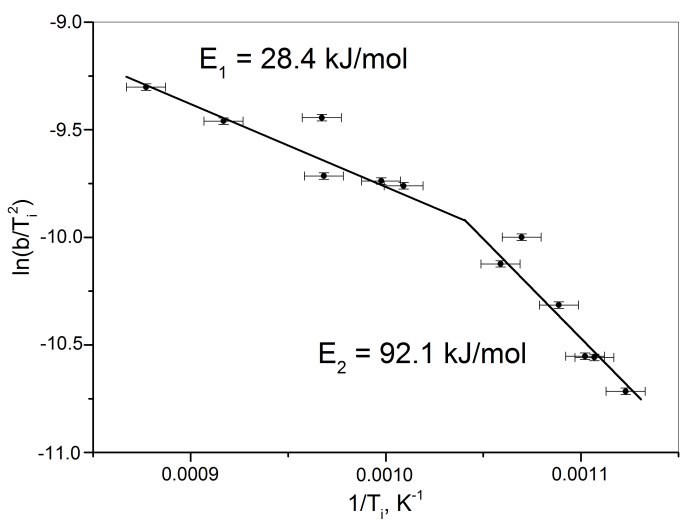

FIG. 6. Evaluation of activation energy in Kissinger coordinates.

tion energies of $\mathrm{Ti}$ and $\mathrm{Al}$ solid state diffusion in different phases of the $\mathrm{Ti}-\mathrm{Al}$ systems, such as $\alpha$-Ti, $\beta$-Ti, Ti ${ }_{3} \mathrm{Al}$, and TiAl, fall in the range $2.59-4.08 \mathrm{eV}(250-394 \mathrm{~kJ} / \mathrm{mol})^{23}$. These values are much higher than the values measured in this work. From the other hand, some experimental study of interfacial reactions in Ti/Al multilayers during diffusion welding, shown that effective activation energy of diffusion decreases dramatically with decreasing atomic fraction of $\mathrm{Ti}^{24}$. Thus, the activation energy for diffusion in the TiAl phase was determined as $250 \mathrm{~kJ} / \mathrm{mol}$, while diffusion in the $\mathrm{TiAl}_{3}$ phase had activation energy about $100 \mathrm{~kJ} / \mathrm{mol}$. Moreover, $\mathrm{TiAl}_{3}$ was a major phase formed dur- 
ing the diffusion welding ${ }^{24}$. Recent works confirmed the leading role of $\mathrm{TiAl}_{3}$ in the interface reaction between $\mathrm{Ti}$ and $\mathrm{Al}$ below melting point of $\mathrm{Al}^{25,26}$. Measurements of the linear growth rate of $\mathrm{TiAl}_{3}$ layer in the temperature range $823-923 \mathrm{~K}$ gave activation energy $128.7 \mathrm{~kJ} / \mathrm{mol}^{26}$. Since the forming has polycrystalline structure with well-developed grain boundaries network ${ }^{25}$, the grain boundary diffusion must be also taken into account. Basing on to the normal parabolic growth of the $\mathrm{TiAl}_{3}$ layer (which was the only phase appeared on the Ti/Al boundary at 823-923 K), activation energy of $33.1 \mathrm{~kJ} / \mathrm{mol}$ was obtained for the low temperature grain boundary diffusion controlled growth, and $296.2 \mathrm{~kJ} / \mathrm{mol}$ - for the high temperature bulk diffusion controlled growth ${ }^{27}$. Overall activation energy of $76.8 \mathrm{~kJ} / \mathrm{mol}$ was accepted for the whole region of the applied annealing temperatures. It is worth noting that all these data were obtained using isothermal annealing method. Comparison with our data measured at non-isothermal conditions allows assumptions that the value of $92.1 \mathrm{~kJ} / \mathrm{mol}$ corresponds to combination of solid-state bulk and grain boundary diffusion, while $28.4 \mathrm{~kJ} / \mathrm{mol}$ may correspond to grain diffusion solely or to liquid phase diffusion in the Al melt. From analogy with other metallic melts, we may expect that activation energy of diffusion in the $\mathrm{Al}$ melt is approximately 5 times smaller that that for the solid-state diffusion ${ }^{28}$. The following MDS results allow deeper insight in the mechanism of interaction.

\section{B. Numerical results}

\section{Reference sample}

The reference system was prepared at different initial temperatures, close to the melting temperature of $\mathrm{Al}, T_{m}(\mathrm{Al})=870 \mathrm{~K}$ (see Table I). For initial temperatures below the melting temperature of $\mathrm{Al}$, the system remains stable. Just a small number of defects appear in the inner layer. The stability of the interface is quite unexpected as compared to prior works on $\mathrm{Ni}-\mathrm{Al}$ system where exothermic phase transformations already appear in solid-state ${ }^{19}$. This is probably due to the very low misfit between (002) Ti-plane and 
(111) Al-plane (see Fig. 7).

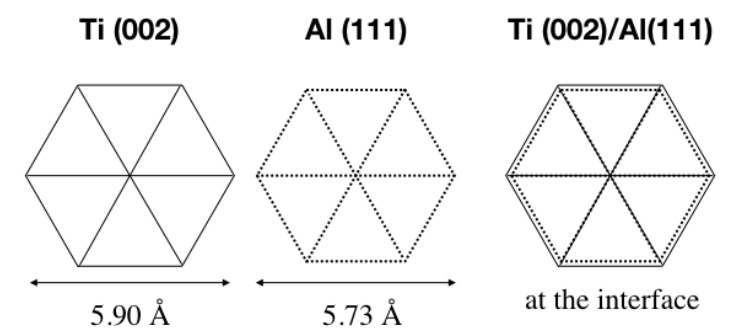

FIG. 7. Atomic arrangement of $\mathrm{Ti}$ and $\mathrm{Al}$ at the interface.

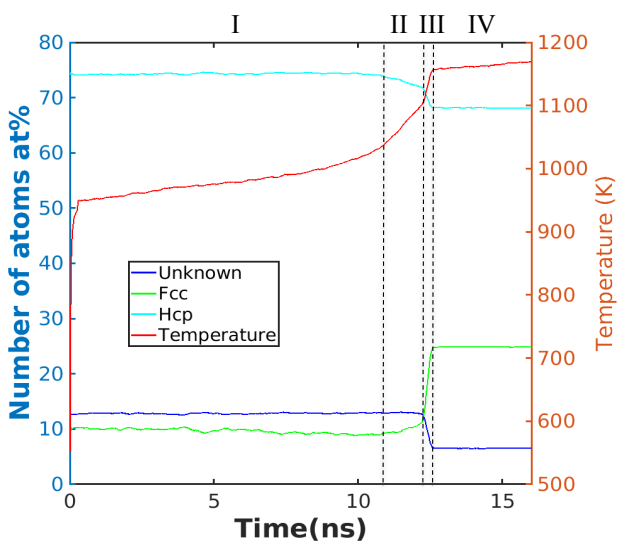

(a)

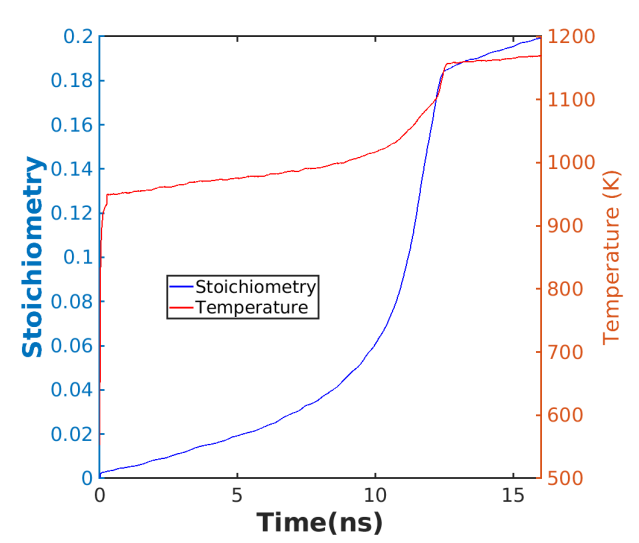

(b)

FIG. 8. (a): Temperature $\mathrm{T}$ (scale in $\mathrm{K}$, on the right) and number of atoms in at\% (on the left) as a function time (scale in ns). The number of atoms in fcc, hcp and unknown configuration are represented. The different stages in the evolution are indicated by the dashed lines. (b): Temperature $T$ (scale in $\mathrm{K}$, on the right) and stoichiometry (on the left) as a function time (scale in ns).

For an initial temperature of $950 \mathrm{~K}$, the situation is completely different. During the thermalization at $950 \mathrm{~K}$, the $\mathrm{Al}$ inner melts and wets the Ti-free surface. During the simulation in adiabatic conditions, the temperature is followed as well as the fraction (at\%) of atoms in the different local configurations (fcc, hcp or unknown). The typical shape of curves in Fig. 8 suggests that the dynamics of the system can be divided into 4 
stages:

I Just after thermalization, from $t=0.4$ to $11 \mathrm{~ns}$ (stage I), the number of amorphous atoms (unknown) and fcc atoms is more or less constant. Amorphous atoms correspond to liquid atoms. The fcc-atoms are located at free surfaces or interfaces. The temperature slowly increases up to $1050 \mathrm{~K}$ and $\xi$ reaches 0.18 .

II During stage II (from $t=11$ to $12 \mathrm{~ns}$ ), the number of hcp-atoms starts to decrease. The temperature reaches $1100 \mathrm{~K}$ and $\xi$ exceeds 0.2 . This stage corresponds to a rapid dissolution of $\mathrm{Ti}$ in the inner layer.

III The stage III is short (less than $0.2 \mathrm{~ns}$, from $t=12.24$ to $12.46 \mathrm{~ns}$ ). More hcp-Ti atoms disappear together with a sudden and short decrease in amorphous atoms. This corresponds to a reorganisation of the inner layer in fcc atoms. The burst in temperature is associated with the crysallization of the inner layer with a stoichiometry around 0.23 .

IV In the last stage (IV), the temperature reaches a plateau. Other indicators are stable. The system is completely crystallized and its structure doesn't changes over time.

The number density profile at $t=0.4 \mathrm{~ns}$ in Fig. 9a shows the amorphization of $\mathrm{Al}$ atoms in the inner layer due to melting. Although the temperature was larger than the melting temperature of $\mathrm{Al}$, the $\mathrm{Al}$ atoms remained arranged in layers close to the interface. During the adiabatic evolution of the system, the $\mathrm{Ti}$ atoms invade the inner layer as the stoichiometric factor $\xi$ progressively increases while the $\mathrm{Al}$ are reorganized in planes (see Fig. 9b). At the interfaces, the transient formation of a solid solution $(\mathrm{Ti}+\mathrm{Al})_{s s}$ was observed. Figure $9 \mathrm{c}$ demonstrates the recrystallization of the inner plane (6 planes) with a well-defined ratio between $\mathrm{Al}$ and Ti atoms. This ratio is slightly less than 0.25 , the one expected for the formation of $\mathrm{TiAl}_{3}$. The Ackland and Jones' analysis shows formation of a fcc-like structure except a twin defect formed by planes in hcp-like structure. 
The increase in temperature is associated with two processes: the reactive dissolution between $\mathrm{Ti}$ and $\mathrm{Al}$ and the spontaneous crystallization of a new phase. The reactive dissolution plays an important role in the catalytic character of the reaction because an increase in temperature favors further dissolution of $\mathrm{Ti}$ in $\mathrm{Al}$. In this simulation, the process of dissolution was interrupted by the phase transformation in an intermetallic compound. Indeed, the stoichiometry in the inner layer increases up to a plateau with a value of 22 at $\%$ of titanium.

The phase transformation could be associated with an exothermic reaction giving rise to the formation of a new compound. If we suppose that $\mathrm{TiAl}_{3}$ is formed:

$$
3 \mathrm{Al}+\mathrm{Ti} \rightarrow \mathrm{TiAl}_{3}
$$

The energy balance expressed in terms of cohesive energies reads

$$
\frac{1}{4}\left[3 \times E_{0}(\mathrm{Al})+E_{0}(\mathrm{Ti})\right]=E_{0}\left(\mathrm{TiAl}_{3}\right)+q
$$

where $q=0.30 \mathrm{eV}$ is the excess energy released by the atomic rearrangement or, equivalently, the formation energy of the compound $\mathrm{TiAl}_{3}$. The intermetallic $\mathrm{TiAl}_{3}$ is characterized by a $\mathrm{DO}_{22}$ structure at high temperature. But the potential developed by Zope and Mishin ${ }^{17}$ gives a very small difference between the two structures $D 0_{22}$ and $L 1_{2}$ of the $\mathrm{TiAl}_{3}$. The structure $L 1_{2}$ is $0.001 \mathrm{eV} /$ atom smaller than the structure $D 0_{22}$. According to this observation, the distinction between these two structures can't be really established in the context of the simulation.

Another simulation was carried out with an initial temperature of $1000 \mathrm{~K}$. The number of atoms and the geometry remained the same. The system was created with the appropriate lattice parameter corresponding to $1000 \mathrm{~K}$. As shown in Fig. 10, the dynamics follows the four stages described previously. During stage II, the temperature rise is even more pronounced. The dissolution is here more important and the stoichiometry reaches a plateau value of 34 at $\%$ and a maximum temperature $T_{\mathrm{ad}}=1300 \mathrm{~K}$. The evolution towards the final temperature is done in a shorter time. 

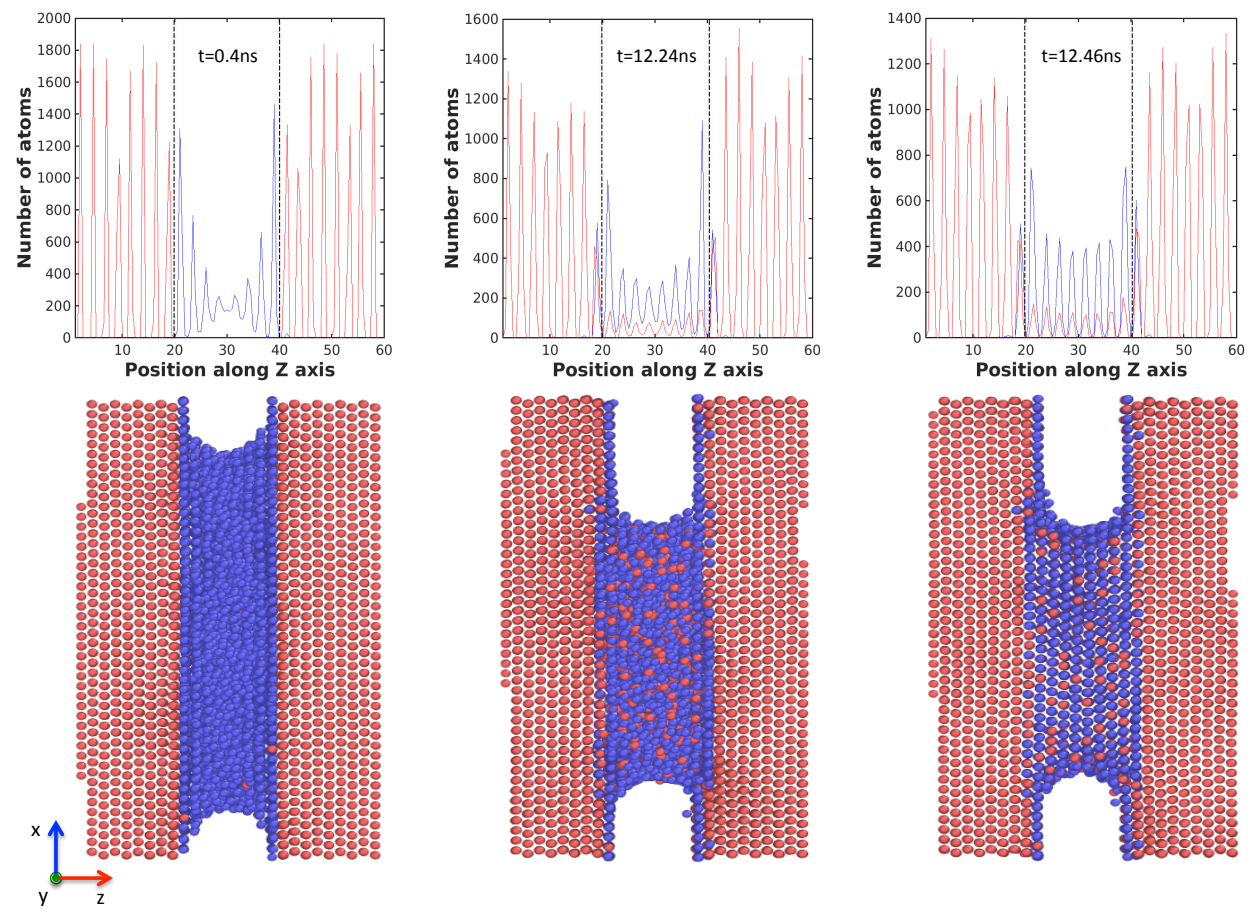

FIG. 9. Number density profiles at $t=0.4,12.24,12.46 \mathrm{~ns}$ in the $z$-direction, perpendicular to the interfaces. The dashed lines indicate the limits of the inner layer in the initial configuration. Corresponding snapshots of the system. Position is measured in Angstroms.

\section{Thick sample}

In order to investigate the size effect, a thick sample was created at $1000 \mathrm{~K}$. We performed the same analysis as previously. In this case, Fig. 11a shows only 3 stages: (I) slow increase in temperature and no configuration change, (II) rapid dissolution of $\mathrm{Ti}$ in the inner layer and (III) saturation toward the adiabatic temperature. The dissolution of $\mathrm{Ti}$ in the inner layer produces a release of heat. The adiabatic temperature is $1315 \mathrm{~K}$ and the saturation of the liquid solution is $\xi=0.35$ as shown in Fig. 11b. No spontaneous crystallization was observed. After the NVE simulation in adiabatic conditions, the inner layer is a liquid solution $(0.35 \mathrm{Ti}+0.65 \mathrm{Al})_{\text {liq. }}$. Figure 12 at $t=5 \mathrm{~ns}$ gives the 


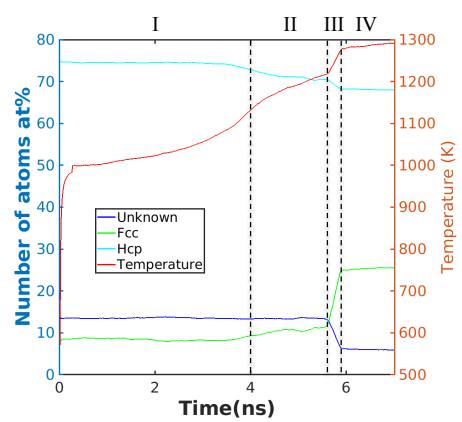

(a)

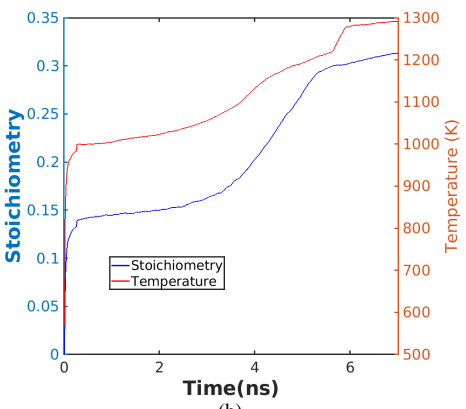

(b)

FIG. 10. Initial temperature of $1000 \mathrm{~K}$. (a): Temperature $T$ (scale in K, on the right) and number of atoms in at\% (on the left) as a function time (scale in ns). The number of atoms in fcc, hcp and unknown configuration are represented. The different stages in the evolution are indicated by the dashed lines. (b): Temperature $T$ (scale in $\mathrm{K}$, on the right) and stoichiometry (on the left) as a function time (scale in $\mathrm{ns}$ ).

number density profile and the corresponding snapshot of the system during stage (I). Although the inner layer is $\mathrm{Al}$ liquid, a structural ordering close to the interfaces was noticed. Figure 12 at $t=20 \mathrm{~ns}$ corresponds to the coexistence of solid outer layers surrounding the liquid solution of Ti and Al. As shown in Fig. 12, $3.5 \mathrm{~ns}$ after the start of the cooling demonstrates the complete reorganization in atomic planes with a constant ratio between $\mathrm{Ti}$ and $\mathrm{Al}$ in each plane. All atoms of the inner layer have a fcc local configuration as proven in Fig. 11c.

Dissolution is the main process in the self-sustained character of the reaction in the Ti-Al system. Above the melting point of $\mathrm{Al}, \mathrm{Ti}$ dissolve in the liquid Al layer. Figure 13 gives the coverage of 4 planes below the lower interface. A similar behavior was observed for the upper interface. The following features were identified:

1. The Ti atoms close to the interfaces leave the solid substrate more easily than atoms located deeper. Nevertheless, the number of liquid atoms (marked as amorphous atoms) doesn't significantly increase.

2. The vacancies liberated by outgoing $\mathrm{Ti}$ atoms are occupied by incoming $\mathrm{Al}$ atoms 


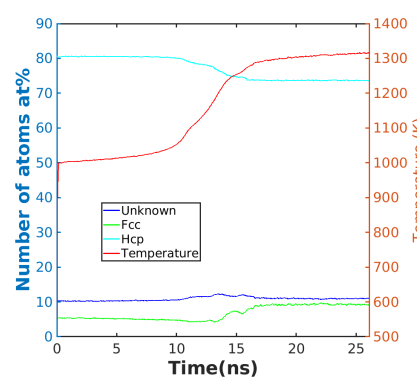

(a)

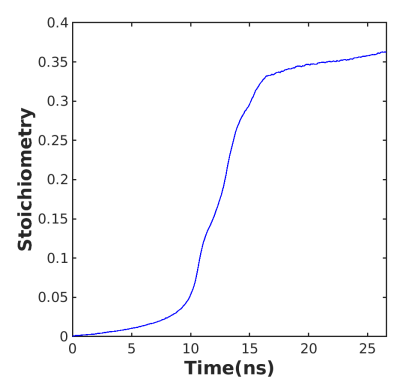

(b)

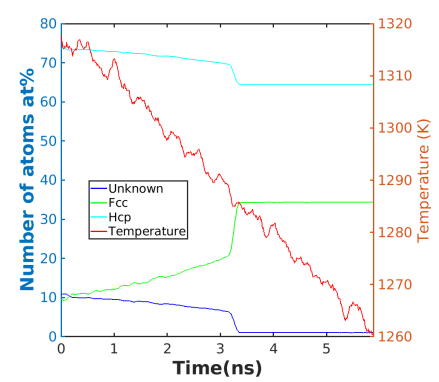

(c)

FIG. 11. Thick sample. Initial temperature of $1000 \mathrm{~K}$. (a): Temperature $T$ (scale in K, on the right) and number of atoms in at\% (on the left) as a function time (scale in ns) during the heating. The number of atoms in fcc, hcp and unknown configuration are represented. (b) Stoichiometry (on the left) as a function time (scale in ns). (c): Temperature $T$ (scale in $\mathrm{K}$, on the right) and number of atoms in at\% (on the left) as a function time (scale in ns) during the cooling.

very quickly. Most $\mathrm{Al}$ atoms adopt a local fcc arrangement while $\mathrm{Ti}$ atoms are becoming liquid. The $\mathrm{Al}$ atoms occupy substitutional positions in the first atomic plane (\#-1) below the interface.

3. The mobility of $\mathrm{Al}$ atoms is limited in outer layers because of the lack of local defects and the inefficient diffusion in solid-phase. As shown in Fig.13, the first plane below the interface is completely depleted by $\mathrm{Ti}$ atoms and progressively covered by $\mathrm{Al}$ atoms. Defects (vacancies and line defects) are created in plane (\# $-1)$.

4. In about $10 \mathrm{~ns}, 50$ at $\%$ of $\mathrm{Ti}$ of the first atomic plane below the interface are dissolved. At $12 \mathrm{~ns}$, the number of Ti reaches a minimum value. Remaining Ti ( $<20$ at $\%$ ) are located on the free surfaces.

5. When the number of $\mathrm{Ti}$ in the plane (\#-1) is significantly reduced, the second plane (\#-2) starts to be depleted and the number of Ti in the plane (\#-1) increases again and reaches a value of 32 at $\%$. The dissolution process operates plane by plane as shown in Fig. 13. 

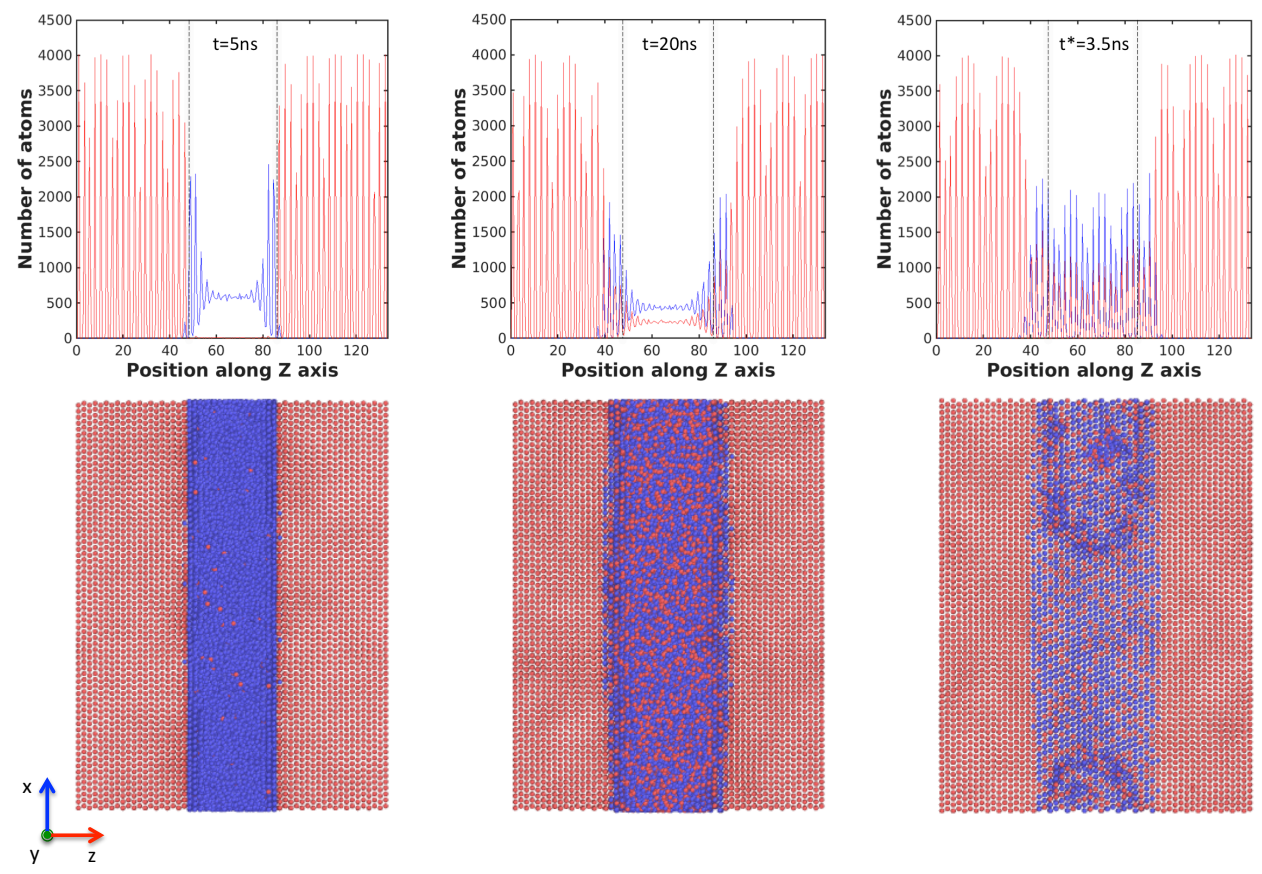

FIG. 12. Number density profiles at $t=5,20 \mathrm{~ns}$ in the $z$-direction, perpendicular to the interfaces, and $3.5 \mathrm{~ns}$ after the start of the cooling. The dashed lines indicate the limits of the inner layer in the initial configuration. Corresponding snapshots of the system. Position is measured in Angstroms.

6. After the dissolution of 70 at $\%$ of Ti atoms in 3 planes, the system reaches a state

$$
\mathrm{Ti}_{\text {sol }}-\left(\mathrm{Ti}_{x}+\mathrm{Al}_{1-x}\right)_{\mathrm{ss}}-\left(\mathrm{Ti}_{y}+\mathrm{Al}_{1-y}\right)_{\text {liq }}
$$

In the case of liquid mixtures, Titanium and Aluminum are characterized by a negative mixing enthalpy:

$$
\Delta H_{\mathrm{mix}}(T)=H_{\mathrm{Ti}-\mathrm{Al}}(T)-\left[\left(1-x_{\mathrm{Ti}}\right) H_{\mathrm{Al}}(T)+x_{\mathrm{Ti}} H_{\mathrm{Ti}}(T)\right]
$$

At the atomistic level, the scheme (Fig. 14) shows the elemental process associated with dissolution: a liquid atom $\mathrm{Al}$ will be exchanged with a solid $\mathrm{Ti}$ atom. As an example, a set of atoms were followed. For instance, the potential energy of the $\mathrm{Al}$ atom in the 


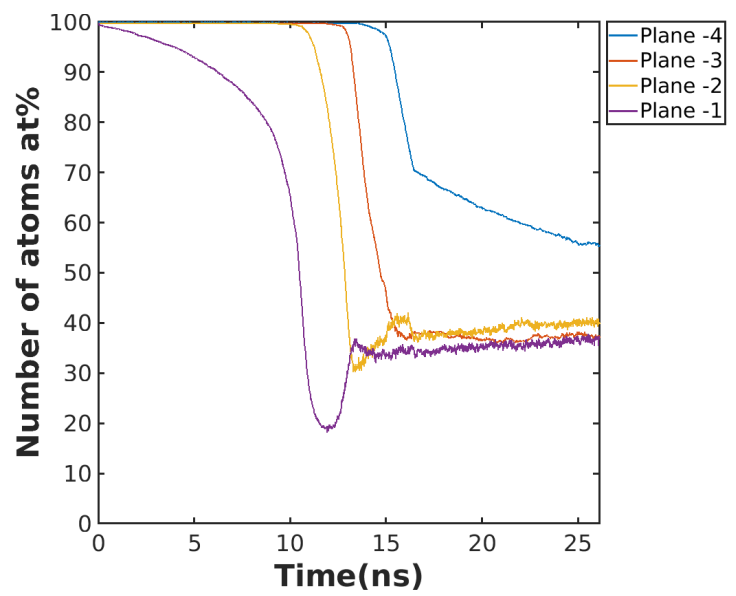

FIG. 13. Number of Ti atoms (at\%) in the atomic planes close to the interface. The plane (\#-1) is the plane just below the interface, the plane (\# -2) is below the plane (\#-1), ....
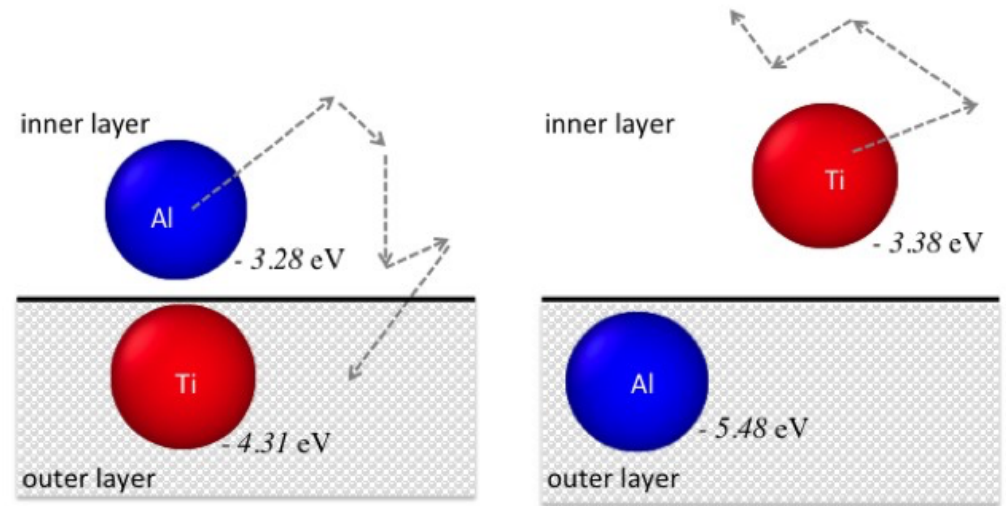

FIG. 14. Number of Ti atoms (at\%) in the atomic planes close to the interface. The plane (\#-1) is the plane just below the interface, the plane (\# -2) is below the plane (\#-1), ....

liquid layer is around $-3.28 \mathrm{eV}$ and decreases to $-5.28 \mathrm{eV}$ when it substitutes a $\mathrm{Ti}$ in the outer solid layer. The $\mathrm{Ti}$ atom in the solid has a potential energy of $-4.31 \mathrm{eV}$ and increases to $-3.38 \mathrm{eV}$ when it disolves in the inner liquid layer. The energetic balance reads:

$$
E\left(\mathrm{Al}_{\mathrm{liq}}\right)+E\left(\mathrm{Ti}_{\mathrm{sol}}\right)=E\left(\mathrm{Al}_{\mathrm{Ti}-\mathrm{sol}}\right)+E\left(\mathrm{Ti}_{\mathrm{Al}-\mathrm{liq}}\right)+q_{\mathrm{diss}}
$$

where $q_{\text {diss }}$ represents the excess of energy release by the dissolution process: the heat 
of dissolution $q_{\text {diss }}=1.27 \mathrm{eV}$. The energy transfer associated with all dissolved atoms induces the increase of $T$ up to $1315 \mathrm{~K}$.

During the exchange between $\mathrm{Al}$ and $\mathrm{Ti}$ atoms, a single incoming $\mathrm{Al}$ atom surrounded by $\mathrm{Ti}$ atoms induces a slight change in the potential energy of Ti nearest neighbours (Fig. 15a). The substitution of several $\mathrm{Al}$ atoms in a vicinity induces a significant modification of neighbouring atoms (Fig. 15b). Such group of atoms will play the role of a nucleus for further dissolution.

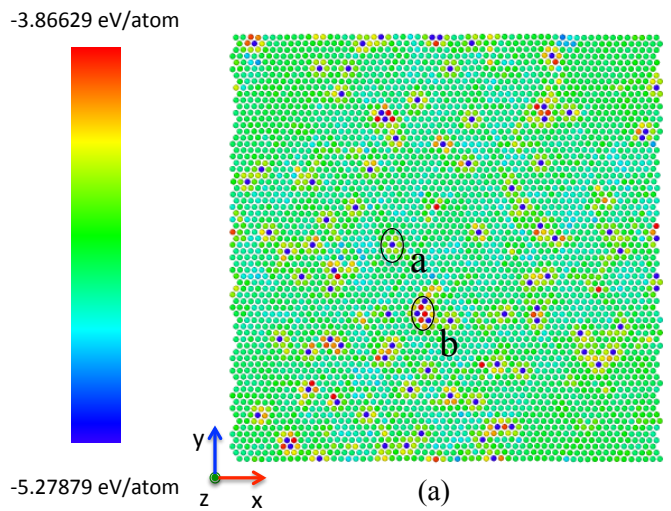

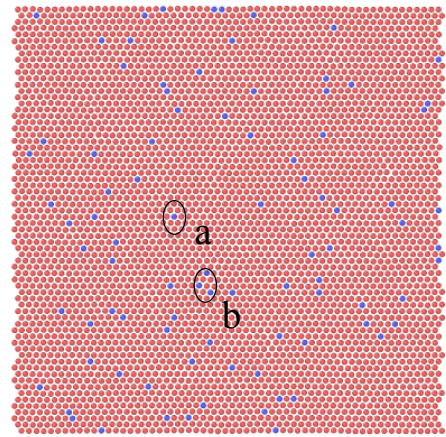

(b)

FIG. 15. Snapshot of atomic plane \#-1. (a): potential energy /atom. (b): species index ( $\mathrm{Al}$ is blue and Ti is red). Time $t=2 \mathrm{~ns}$.

\section{CONCLUSIONS}

The reactivity of the Ti-Al system has been studied by means of molecular dynamics simulations and experiments. The main features are as follows:

- No reaction occurs at a temperature below the melting point of Al. The interface between (002)-Ti plane and (111)-Al plane is very stable due to the small mismatch between the two structures. In addition, the metallic radius of Ti is slightly larger than the $\mathrm{Al}$ metallic radius:

$$
r_{\text {metal }}(\mathrm{Ti})=1.47 \mathrm{pm} \quad r_{\text {metal }}(\mathrm{Al})=1.43 \mathrm{pm}
$$


This fact explains the lack of solubility of $\mathrm{Ti}$ in $\mathrm{Al}$ solid.

- When the system is heated above the melting temperature of $\mathrm{Al}$, we observed an exothermic self-sustained dynamics until a plateau value of $\mathrm{T}$ is reached. The behavior is similar to the phenomenon of adiabatic explosion.

- The first phase transformation to occur at high temperature is the amorphization of the $\mathrm{Al}$ inner layer, except close the interfaces where $\mathrm{Al}$ exhibits a structural ordering.

- The dissolution of $\mathrm{Ti}$ in $\mathrm{Al}$ is associated with an exothermic mixing of the two metals. The heat released due to dissolution is the main heat source.

- The dissolution operates as an exchange of $\mathrm{Ti}$ and $\mathrm{Al}$ atoms at interfaces. There is no net flux at the interface.

- The adiabatic temperature depends on the initial temperature value. The same is true for the saturation value of the liquid solution.

- The spontaneous formation of an intermetallic compound was only observed in the small systems. The phase transformation is very rapid (less than $0.2 \mathrm{~ns}$ ).

- In the large system, the crystallization of the intermetallic compound occurs during the cooling simulation at $2988 \mathrm{~K}$. The growth of the intermetallic develops plane by plane starting from the interface.

- The intermetallic compound is $\left(\mathrm{Ti}_{y} \mathrm{Al}_{1-y}\right)$ with $y \sim 0.3$. The interatomic potential developed by Zope and Mishin predicts a single Al-rich phase $\operatorname{Ti}_{0.25} \mathrm{Al}_{0.75} \equiv$ $\mathrm{TiAl}_{3}$. The simulation results demonstrate the formation of an intermetallic with a well-defined composition and a local fcc configuration, close to the $\mathrm{TiAl}_{3}$ compound. As shown in Fig.16, the $\mathrm{TiAl}_{3}$ intermetallic can easily grow on a Ti plane. Substitution of Ti atoms by $\mathrm{Al}$ ones and a slight displacement of 
Ti gives the specific structure. Moreover the $D 0_{22}$ structure is based on a face centered cubic structure.
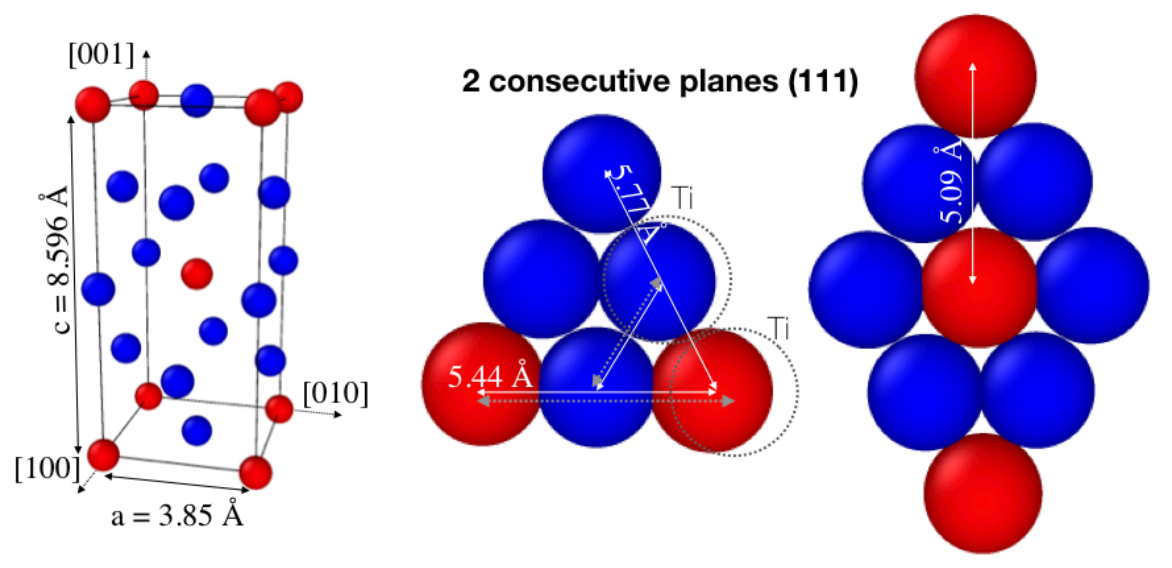

FIG. 16. $\mathrm{DO}_{22}$ crystallographic structure of $\mathrm{TiAl}_{3}$ and two consecutive (111) planes in $\mathrm{TiAl}_{3}$. The (002) plane of pure $\mathrm{Ti}$ is shown in dashed. $\mathrm{Al}$ in blue and $\mathrm{Ti}$ in red.

\section{ACKNOWLEDGMENTS}

This work is supported by the International Russian-French PHC Kolmogorov "RECIPES" (Campus France no. 41144SG), the Ministry of Science and Higher Education of the Russian Federation in the framework of the Federal Target Program "Research and Development on Priority Directions of the Scientific and Production Complex of Russia for 2014-2020", agreement no. 14.587.21.0051, project RFMEFI58718X0051. The use of computational facilities at the Computing Center of the University of Bourgogne, PSIUN-CCUB, is gratefully acknowledged.

\section{Data Availability Statement}

The data that support the findings of this study are available from the corresponding author upon reasonable request. 


\begin{tabular}{|c|c|c|c|}
\hline \multicolumn{4}{|c|}{ Thermal expansion } \\
\hline metal/phase & $\mathrm{A}(\AA)$ & $\mathrm{B}(\AA / K)$ & $\mathrm{C}\left(\AA / K^{2}\right)$ \\
\hline $\mathrm{Al}$ & 4.05 & $4.868 \times 105$ & $4.237 \times 108$ \\
$\mathrm{Ti}$ & 2.951 & $3.377 \times 106$ & $9.929 \times 109$ \\
$\mathrm{TiAl}$ & 3.998 & $4.273 \times 105$ & $1.811 \times 108$ \\
$\mathrm{TiAl}_{3}$ & 4.049 & $5.638 \times 105$ & $2.688 \times 108$ \\
\hline
\end{tabular}

TABLE III. Coefficients $A, B$ and $C$ for the parabolic fit $a(T)=A+B T+C T^{2}$ giving the lattice parameter dependences on temperature for pure $\mathrm{Ti}$ and $\mathrm{Al}$ metals, and for the intermetallic compounds. These values were computed for the Zope and Mishin EAM potential ${ }^{17}$.

\section{Appendix}

The temperature evolution of the lattice parameter was investigated to determine the thermal expansion coefficient $\alpha=[a(T)-a(298 K)] / a(298 K) \times 100 \%$, where $a(T)$ is the lattice parameter at $T$. The method used to calculate the thermal expansion is in 3 steps. (1) the system is heated in the NVT ensemble during $50 \mathrm{ps}$ with a temperature ramp of 10. (2) The system is relaxed in the NPT ensemble during $50 \mathrm{ps}$ at a constant temperature. During this stage, the system adjust its volume. (3) The system is then simulated in the NVE ensemble during 10 ps. All the measurements are done in this part. The 3 steps making up one cycle are repeated during the simulation. The temperature is heated from $10 \mathrm{~K}$ to the melting point in order to get the thermal expansion in the solid phase. The temperature dependence of the lattice parameter was approximated by using a parabolic fit $a(T)=A+B T+C T^{2}$. The corresponding values of the coefficients $A$, $B$, and $C$ are reported in Table III. 


\section{REFERENCES}

${ }^{1}$ H. Chowdhury, H. Altenbach, M. Krüger, K. Naumenko, Mech. Adv. Mater. Mod. Process. 3, 55-20 (2017).

${ }^{2}$ A. A. Nepapushev, D. O. Moskovskikh, V. S. Buinevich, S. G. Vadchenko, A. S. Rogachev, Metall. Mater. Trans. 50B, 1241-1247 (2019).

${ }^{3}$ S.P. Kiselev, N.S. Ryashin, Proceedings of the 18th International Conference on the Methods of Aerophysical Research, 030093-4 (2019).

${ }^{4}$ A.S. Mukasyan, A.S. Rogachev, S.T. Aruna, Combustion synthesis in nanostructured reactive systems, Adv. Powder Technol. 26, 954-976 (2015).

${ }^{5}$ S. Sen, M. Lake, J. Wilden, P. Schaaf, Thin Solid Films 631, 99-105 (2017).

${ }^{6}$ S. Sen, M. Lake, P. Schaaf, Appl. Surf Sci. 474, 243-249 (2019).

${ }^{7}$ E. Illeková, J.-C. Gachon, A. Rogachev, H. Grigoryan, J.C. Schuster, A. Nosyrev, et al., Thermochimica Acta. 469, 77-85 (2008).

${ }^{8}$ J.C. Gachon, A.S. Rogachev, H.E. Grigoryan, E.V. Illarionova, J.J. Kuntz, D.Y. Kovalev, et al., Acta Mater. 53, 1225-1231 (2005).

${ }^{9}$ F. Baras, V. Turlo, O. Politano, S.G. Vadchenko, A.S. Rogachev, A.S. Mukasyan, Adv. Eng. Mater. 20, 1800091-20 (2018).

${ }^{10}$ E.V. Levchenko, A.V. Evteev, G.G. Löwisch, I.V. Belova, G.E. Murch, Intermetallics 22, 193-202 (2012).

${ }^{11}$ E.V. Levchenko, A.V. Evteev, T. Lorscheider, I.V. Belova, G.E. Murch, Comput. Mater. Sci. 79, 316-325 (2013).

${ }^{12}$ S.P. Kiselev, E.Z. Zhirov, Intermetallics 49, 106114 (2014).

${ }^{13}$ S. Kiselev, Dokl. Phys. 466, 406-408 (2016).

${ }^{14}$ J. Wang, A. Horsfield, P.D. Lee, P. Brommer, Phys. Rev. B. 82, 144203 (2010).

${ }^{15}$ H.E. Kissinger, Anal. Chem. 29, 1702-1706 (1957).

${ }^{16}$ S. Plimpton, J. Comput. Phys. 117, 1-19 (1995).

${ }^{17}$ R.R. Zope, Y. Mishin, Phys. Rev. B 68, 30-14 (2003) 
${ }^{18}$ V. Turlo, F. Baras and O. Politano, Modelling Simul. Mater. Sci. Eng. 25, 064002 (2017).

${ }^{19}$ F. Baras, O. Politano, Phys. Rev. B 84, 024113 (2011).

${ }^{20}$ G. Ackland, A. Jones, Phys. Rev. B 73, 054104 (2006).

${ }^{21}$ A. Stukowski, Modelling Simul. Mater. Sci. Eng. 18, 015012-7 (2009) .

${ }^{22}$ A.S. Rogachev, N.F. Shkodich, S.G. Vadchenko, F. Baras, D.Yu. Kovalev, S. Rouvimov, A.A. Nepapushev, A.S. Mukasyan, J. Alloys Compds. 577 600-605 (2013).

${ }^{23}$ Y. Mishin, C. Herzig, Acta Mater. 48, 589-623 (2000).

${ }^{24}$ J.-G.Luo, V.L. Acoff, Supplement to the Welding Journal. 239-s-243-s (2000).

${ }^{25}$ N. Thiyaneshwaran, K. Sivaprasad, B. Ravisankar, Scientific Reports 8:16797(1-8) (2018).

${ }^{26}$ A.H. Assari, B. Eghbali, Phys. Met. Metallogr. 120, 260-268 (2019).

${ }^{27}$ M. Mirjalili, M. Soltanieh, K. Matsuura, M. Ohno, Intermetallics 32, 297-302 (2013).

${ }^{28}$ T. Gorecki, J. Mater. Sci. Lett. 9, 167-169 (1990) 